\title{
Selective Harmonic Elimination of an Eleven Level Inverter Using Whale Optimization Technique
}

Srikanta Kumar Dash, Byamakesh Nayak, Jiban Ballav Sahu

School of Electrical Engineering, KIIT University, India

\begin{tabular}{l}
\hline \hline Article Info \\
\hline Article history: \\
Received Jun 22, 2018 \\
Revised Aug 22, 2018 \\
Accepted Sep 11, 2018 \\
\hline Keyword: \\
Selective harmonic elimination \\
Cascade multilevel inverter \\
Total harmonic distortion \\
Whale optimization technique \\
Separate D.C. Sources
\end{tabular}

\section{Corresponding Author:}

\begin{abstract}
Reduction of total harmonic distortion in multilevel inverters is a difficult optimization problem that includes nonlinear transcendent equations having more than one local minima.The task becomes difficult as the level of the cascaded multilevel inverter increases.Optimization techniques helps in finding out the solution in a very less span of time giving the best possible results. This paper deals with the harmonic elimination of cascaded multilevel inverter with equal D.C. sources using a new optimization technique called Whale optimization technique. The objective of this paper is to find the best combination of switching angles to minimize the lower order harmonics and the total harmonic distortion is reduced. This aforesaid algorithm is applied to an 11-level cascaded H-bridge inverter.Results shows that Whale optimization algorithm gives better results and effectively performs the above mentioned task.
\end{abstract}

Copyright @ 2018 Institute of Advanced Engineering and Science. All rights reserved.

Srikanta kumar Dash,

School of Electrical Engineering, KIIT University,

Bhubaneswar, Odisha, India.

Email:srikantdash12@gmail.com

\section{INTRODUCTION}

Multilevel inverters have gained a lot of interest in the past decade for increasing the voltage to different levels which make it suitable for medium and large power applications like statcom, electric drives, renewable energy, etc. The $\mathrm{H}$ bridge inverter previously produces an output voltage of $\mathrm{V}_{\mathrm{dc}}, 0,-\mathrm{V}_{\mathrm{dc}}$. This basic $\mathrm{H}$ bridge switching technique is extended to other circuits that can generate added output voltage levels. This multilevel output voltage gives a staircase waveform which is similar to sinusoidal waveform thus reducing the harmonic content in the output. There are different type of multilevel inverter topologies like neutral point clamped, flying capacitor and cascaded inverter out of which the cascaded multilevel inverter has gained a lot of popularity due to its improved quality and connection of independent d.c sources (SDCS) to each of the module so as to attain high power level at the output.[1]-[2]The cascaded multilevel inverter(CMLI) is very efficient in minimizing THD and gives better quality of power.It is animportant topology as it is more simplein obtaining the preferred output voltage from several D.C. sources contrast to diode-clamped and flying capacitors type multilevel inverters. The utility of a multilevel inverter (MLI).[3] It has a modular structure with simple switching method and occupies a lesser space. By connectingadequate number of H-bridges in cascade along with a properly choosen switching scheme, a nearly sinusoidal output voltage waveform can be obtained. Each $\mathrm{H}$ Bridge operates with a different switching scheme which is used for harmonic control. If the number of H-bridge given by's' then the no level of output voltage obtained per phase in CMLI is $2 \mathrm{~s}+1$. Each $\mathrm{H}$ Bridge operates at a different delay angle resulting in a staircase waveform of the output phase voltage where the output voltage is the sum of all voltage generated by H Bridge. [4]-[5] The output phase and line voltage obtained and the efficiency of DC to AC conversion depends on the THD. Normally the output voltage waveform of a single phase inverter contains 33.5 percent of third harmonics, 20 percent of fifth harmonics and 14.5 percent of seventh harmonics approximately. As the output voltage in 
CMLI is obtained by the synthesis of many D.C. Sources to get the desirable a.c. value, hence it is essential to minimize the harmonics and to keep the total harmonic distortion (THD) within the specified limits prescribed by IEEE standards.[6]This paper is organized as follows. In section II the SHE and mathematical equations of SHE are given followed by the introduction of WOA is section III. In section IV WOA is applied in harmonic elimination problem to find out best switching angles is presented along with the results and discussion for an11-level inverter. This includes the calculation of THD, and the elimination of the 5th, 7th, 11th, 13th harmonics at various modulation index is given followed by conclusion in section $\mathrm{V}$.

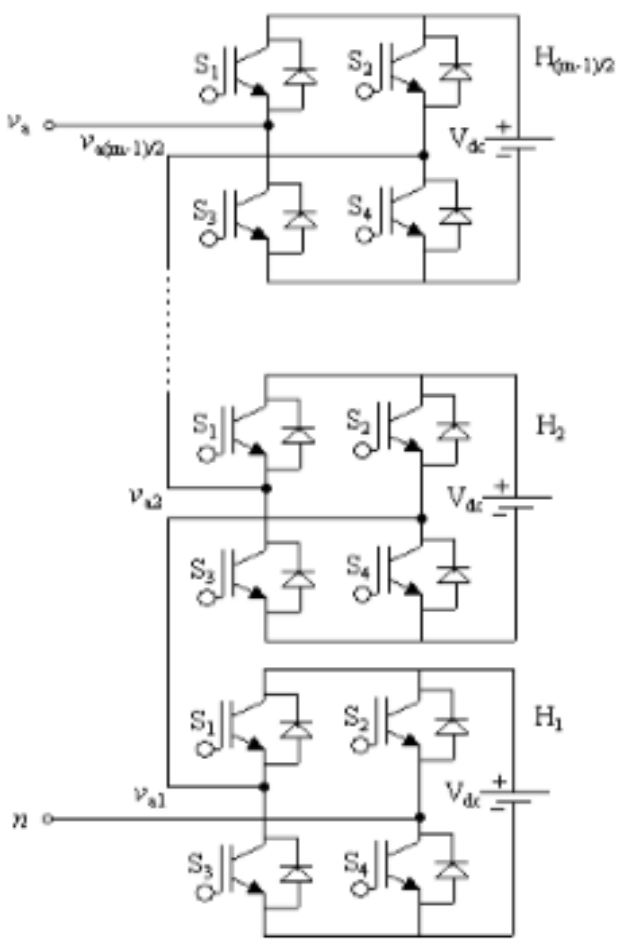

Figure 1. Configuration of CMLI

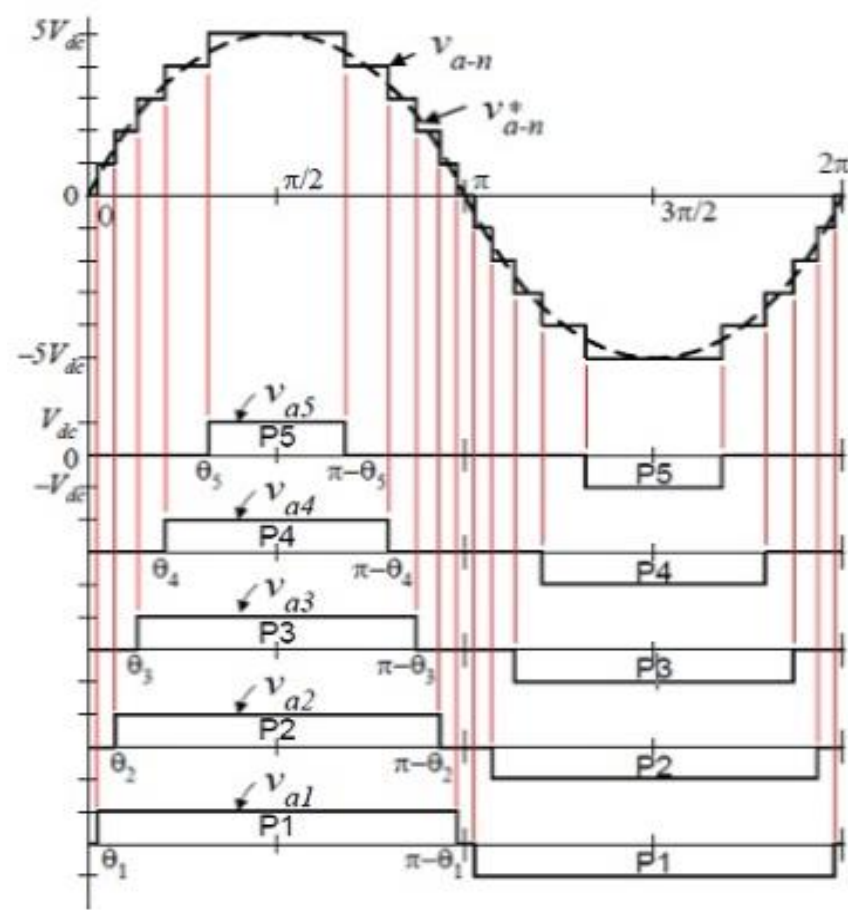

Figure 2. Pulse width if CMLI

\section{SHE EQUATIONS FOR A CASCADE MULTILEVEL INVERTER}

In SHE-PWM technique the switching angles are generated to cancel a set of lower order harmonics at fundamental frequency[7]. Figure 1 shows configuration of CMLI. The output voltage waveform obtained in a CMLI is a staircase waveform as shown in Figure 2. As per the Fourier series of staircase waveform the even harmonics are less problematic with respect to the odd harmonics. Hence the harmonics those are to be eliminated are $3,5,7 \ldots$, up to k-1 harmonics. For the elimination of k-1 harmonics, $\mathrm{k}$ number of switching angles are to be generated.[8]-[9] In balanced three-phase, the third harmonics is negligible in line voltage whereas present in-phase voltage and therefore it is possible to reject $5^{\text {th }}, 7$ th, 11 th, etc from the line voltage waveform at a low switching frequency [10]. The output voltage waveform is given by

$$
V(w t)=\left\{\sum_{n=1,3,5 \ldots}^{\infty} \frac{4 \mathrm{v}_{\mathrm{dc}}}{\mathrm{n} \pi}\left(\cos \left(\mathrm{n} \alpha_{\mathrm{k}}\right) \sin \mathrm{nwt}\right)\right\}
$$

Where $\mathrm{n}$ is the harmonic number and constraints of $0 \leq \alpha_{1} \leq \alpha_{2} \leq \alpha_{3} \leq \alpha_{4} \leq \alpha_{5} \leq \frac{\pi}{2}$. The objective of this paper is to calculate the optimum switching angles $\alpha_{1}, \alpha_{2}, \alpha_{3}, \alpha_{4}, \alpha_{5}$ for an 11 level inverter having equal voltage sources i.e. $\mathrm{V}_{1=} \mathrm{V}_{2=} \mathrm{V}_{3=} \mathrm{V}_{4=} \mathrm{V}_{5=} \mathrm{V}$

$5 m=\cos \alpha_{1}+\cos \alpha_{2}+\cos \alpha_{3}+\cos \alpha_{4}+\cos \alpha_{5}$

$0=\cos 5 \alpha_{1}+\cos 5 \alpha_{2}+\cos 5 \alpha_{3}+\cos 5 \alpha_{4}+\cos 5 \alpha_{5}$

$0=\cos 7 \alpha_{1}+\cos 7 \alpha_{2}+\cos 7 \alpha_{3}+\cos 7 \alpha_{4}+\cos 7 \alpha_{5}$

$0=\cos 11 \alpha_{1}+\cos 11 \alpha_{2}+\cos 11 \alpha_{3}+\cos 11 \alpha_{4}+\cos 11 \alpha_{5}$ 


$$
0=\cos 13 \alpha_{1}+\cos 13 \alpha_{2}+\cos 13 \alpha_{3}+\cos 13 \alpha_{4}+\cos 13 \alpha_{5}
$$

Here Modulation index $\left(\mathrm{M}_{\mathrm{a}}\right)=$ the ratio of the $1^{\text {st }}$ harmonic component of voltage to the maximum attainable voltage. If the maximum $1^{\text {st }}$ harmonic or fundamental voltage is $V_{1}$ and the d.c voltage is equal to $\mathrm{V}_{\mathrm{dc}}$. [11]

$$
\begin{aligned}
& \mathrm{M}_{\mathrm{a}=} \frac{\mathrm{V}_{1} \pi}{4 \mathrm{KV} \mathrm{V}_{\mathrm{dc}}}=\frac{\cos \alpha_{1}+\cos \alpha_{2}+\cos \alpha_{3}+\cos \alpha_{4}+\cos \alpha_{5}}{k} \\
& \text { Again, the expression of THD }=\sqrt{\left(\frac{\sum_{\mathrm{k}}^{\infty} \mathrm{v}_{\mathrm{k}}^{2}}{\mathrm{v}_{1}{ }^{2}}\right)} \text { where } \mathrm{k}=3,5,7,11 \ldots
\end{aligned}
$$

And $\mathrm{v}_{1}$ is the fundamental component of voltage and $\mathrm{k}$ is the harmonic number.

\subsection{Problem Formulation of Selective Harmonic Elimination Using WOA}

The objective function is given below [12]. For elimination of harmonics, each term of the function $F\left(\alpha_{i}\right)$ should be equal to zero where $\alpha_{i}$ is the switching angles.

$$
\begin{gathered}
F\left(\alpha_{i}\right)=\left(\sum_{i=1}^{5} \cos \left(\alpha_{i}\right)-5 m\right)^{2}+\left(\frac{4}{5 \pi} \sum_{i=1}^{5} \cos \left(5 \alpha_{i}\right)\right)^{2}+ \\
\left(\frac{4}{7 \pi} \sum_{i=1}^{5} \cos \left(7 \alpha_{i}\right)\right)^{2}+\left(\frac{4}{11 \pi} \sum_{i=1}^{5} \cos \left(11 \alpha_{i}\right)\right)^{2}+ \\
\left(\frac{4}{13 \pi} \sum_{i=1}^{5} \cos \left(13 \alpha_{i}\right)\right)^{2} \text { With a constraints } 0 \leq \alpha_{i} \leq \frac{\pi}{2}
\end{gathered}
$$

\section{WHALE OPTIMIZATION ALGORITHM (WOA)}

Whale optimization algorithm is anew metaheuristic optimization algorithm based on the hunting activities of humpback whales. [13]. The humpback whales are very brainy mammals that like to hunt krill or small fishes nearer to surface of the sea. They move in a 9 shaped path forming a unique bubble to deceive the small fishes.This method is quite unique in humpback whales. The mathematical model of WOA is divided into three parts encircling of prey followed by bubble net hunting method and Search the prey.

\subsection{Encircling Prey}

WOA technique considers thepresent best candidate solution is close to finest results. The leader among the humpback whale is defined first and other humpback whales followthe leader in hunting. The mathematical equation of above behaviour is given by

$$
\begin{aligned}
& \vec{D}=|\overrightarrow{\mathrm{C}} \cdot \overrightarrow{\mathrm{X}} *(t)-\overrightarrow{X(t)}| \\
& \overrightarrow{\mathrm{X}}(t+1)=\overrightarrow{\mathrm{X}} *(t)-\vec{A} \cdot \vec{D} \\
& \vec{A}=2 \vec{a} \cdot \vec{r}-\vec{a} \\
& \vec{C}=2 \cdot \vec{r}
\end{aligned}
$$

Where ' $t$ ' designates the present iteration $\overrightarrow{X^{*}}$ is the location of the result attained which is updated after every reiteration for getting improved outcomes. Equation (6) gives the absolute value, 'a' shrinks linearly from 2 to 0 and ' $r$ ' is a random vector between 0 and 1 .

\subsection{Bubble Net Attacking Method}

This method is the exploitation stage and the mathematical model of this method is as follows a. Shrinking Encircling Method

This performance is attained by shrinking the value of ' $a$ ' in Equation (8). The function range of ' $A$ ' is by ' $a$ '. A will move alsodecreasedfrom $(X, Y)$ to $\left(X^{*} Y^{*}\right)$ for $0 \leq \mathrm{A} \leq 1$.

b. Spiral updating position

In hunting, humpback whales swim around the prey in shrinking circle and along a spiral-shaped path at the same time. Here $50 \%$ chance among shrinking, encircling or the spiral model to update the position of the whales and target to mimic the helix-shaped movement are as follows: 


$$
\begin{aligned}
& \overrightarrow{\mathrm{X}}(t+1)=\overrightarrow{\mathrm{D}} * e^{b l} \cos 2 \pi \mathrm{l}+\overrightarrow{X^{*}}(t) \\
& \vec{D}=\overrightarrow{\mid X^{*}(t)}-\vec{X}(t) \mid
\end{aligned}
$$

and shows the distance of ith whale to the location of thetarget.b is a constant for describing the profile of logarithmic spiral, 1 is a random number $[-1,1]$ and is part by part multiplication. Humpback whales swim around the prey within a shrinking circle and along the spiral-shaped path simultaneously. Taking a chance of $50 \%$ for both mechanisms, we get equations as follows.

$$
\begin{aligned}
& \overrightarrow{\mathrm{X}}(t+1)=\overrightarrow{\mathrm{D}} * e^{b l} \cos 2 \pi \mathrm{l}+\overrightarrow{X^{*}} \cdot \vec{D} \text { If } \mathrm{P}>0.5 \\
& \overrightarrow{\mathrm{X}}(t+1)=\overrightarrow{\mathrm{X}} *(t)-\vec{A} \cdot \vec{D} \text { if } \mathrm{P}<0.5
\end{aligned}
$$

Here $\mathrm{P}$ is a random number between $[0,1]$

\subsection{Search for Prey}

To get the overall finest values updating has been done with randomly chosen search agent rather than the best agent. Xrand is the random whales in the current iteration. The equations are given as

$$
\begin{aligned}
& \overrightarrow{\mathrm{X}}(t+1)=\overrightarrow{X_{\text {rand }}}-\vec{A} \cdot \vec{D} \\
& \overrightarrow{\mathrm{D}}=\left|\vec{C} \cdot \overrightarrow{X_{\text {rand }}}-\vec{X}\right|
\end{aligned}
$$

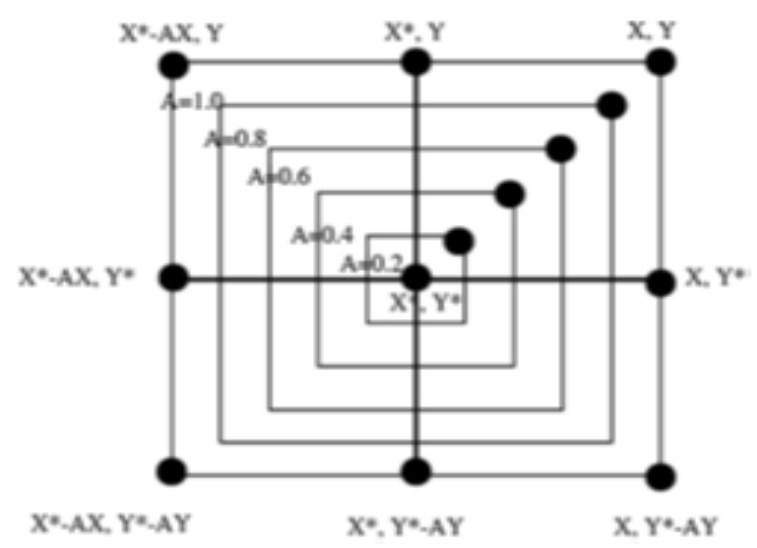

Figure 3. Bubble net search shrinking encircling mechanism

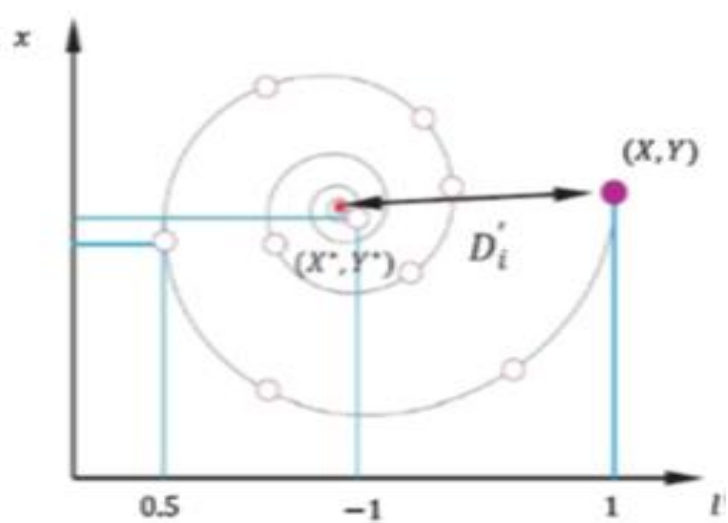

Figure 4. Bubble net search spiral updating position mechanism

\subsection{WOA Algorithm and Flowchart [14]}

a State population size, parameters, maximum number of iterations

b Set the repetition counter.

c Fitness function $F\left(\alpha_{i}\right)$ is considered and preliminary population is generated arbitrarily

d Search agent are estimated and finest search agent is assigned the job

e Repetition counter is increased $\mathrm{t}=\mathrm{t}+1$

f All constraints like a, A, C, P, etc are updated

$\mathrm{g}$ Exploration and exploitation are applied as per the values of Pand A.

h Repeat step 5, 6, 7 till end criteria satisfies.

i Write the solution

j End 


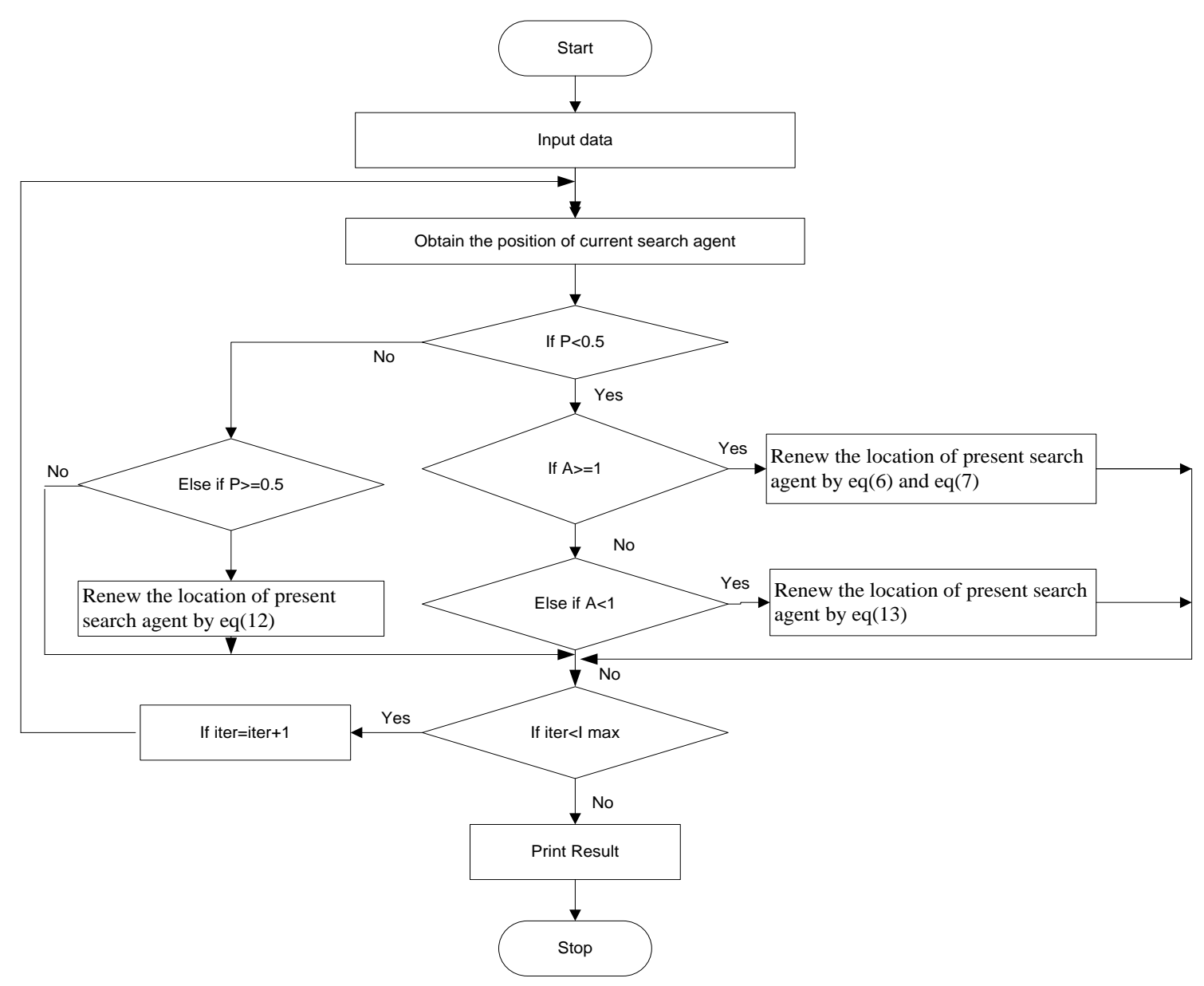

\section{RESULTS AND DISCUSSIONS}

Metaheuristic optimization algorithm plays an essential role in finding out optimum switching angles required for elimination of harmonics. As the level of the multilevel inverter increases, the no of variables in the objective function given in Equation 5 also increases which makes the problem more complicated. The whale optimization algorithm is a new algorithm which performs the above task effectively. This algorithm has many benefits as it can give all possible answer in the form of switching angles for any level of multilevel inverter at a quicker speed of convergence, etc. . In order to test the performance of algorithm, an eleven level inverter is taken and a supply voltage of $50 \mathrm{~V}$ is applied to each of the Five H Bridge connected in cascade. In this paper, the maximum number of iterations taken for WOA is 500 , the population of search agents is 30 and the dimensions are 5 . The program is run for many times and the best results were taken into consideration. Figure 5 shows the optimum switching angles generated at different modulation index with the help of above-mentioned algorithm and with the objective to minimize THD. It is observed in Figure 6 and Figure 7 thatTHD in line voltages decreases with the increase in the modulation index and the fundamental component increases with increase in modulation index respectively. The results show that the low-order harmonics of the line voltage are very lesser in magnitude and are suppressed effectively at various modulation index and results are given in table-1. Because of the 120 phase shifts between R, Yand B phase voltages, all third harmonics component in line voltages are also very small. The THD is found out to be $4.25 \%$ at a modulation index of 0.8 . Higher order harmonics are of very less in magnitude in comparison to the lower order harmonics for various applications of electric drives, etc. It is observed that results are improved with WOA algorithm when it is compared with other algorithms. Figure 8(a) and Figure 8(b) shows the line voltage and phase voltage waveform at optimum switching angles. At each modulation index, the program was run many times for finding out the optimum switching angles and the graph of the best score obtained with respect to modulation index is given in Figure 9. Finally the convergence curve in Fig-10 shows that the above algorithm converges faster and has the ability to escape local minima. A comparative analysis of the performance of whale optimization algorithm and other algorithms are also given in Table 2. 
Table 1. THD Calculation of $5^{\text {th }}, 7$ th, 11 th, 13 th Harmonics

\begin{tabular}{ccccccc}
\hline Modulation & \multicolumn{7}{c}{ Switching angles in radians } & \multirow{2}{*}{ \% THD } \\
\cline { 2 - 6 } index 'Ma' & $\alpha_{1}$ & $\alpha_{2}$ & $\alpha_{3}$ & $\alpha_{4}$ & $\alpha_{5}$ & \\
\hline 0.5 & 0.6201 & 0.7935 & 0.9957 & 1.211 & 1.4828 & 1.04 \\
0.6 & 0.4607 & 0.76195 & 0.9039 & 1.0857 & 1.2662 & 1.1 \\
0.7 & 0.1441 & 0.4994 & 0.7213 & 0.9327 & 1.2804 & 0.7 \\
0.8 & 0.116 & 0.3295 & 0.4764 & 0.7887 & 1.086 & 0.6 \\
\hline
\end{tabular}

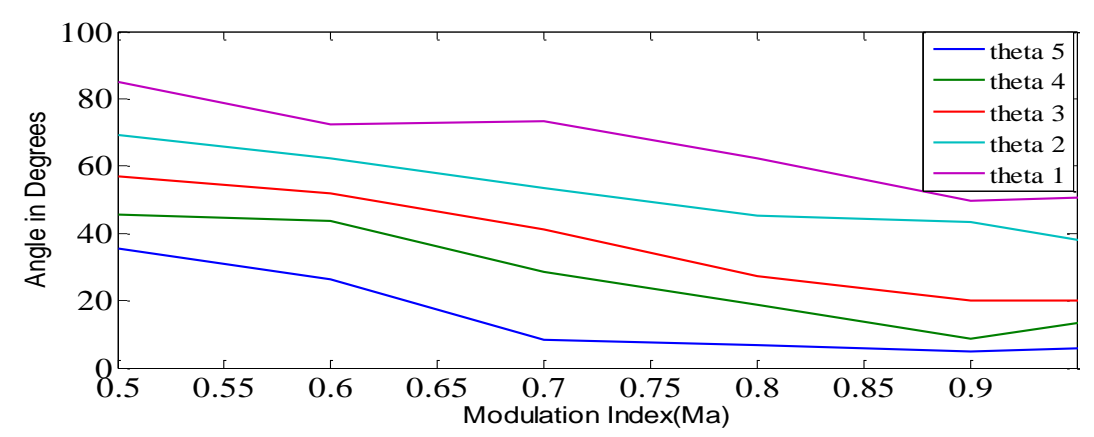

Figure 5. Switching Angles vs Modulation Index

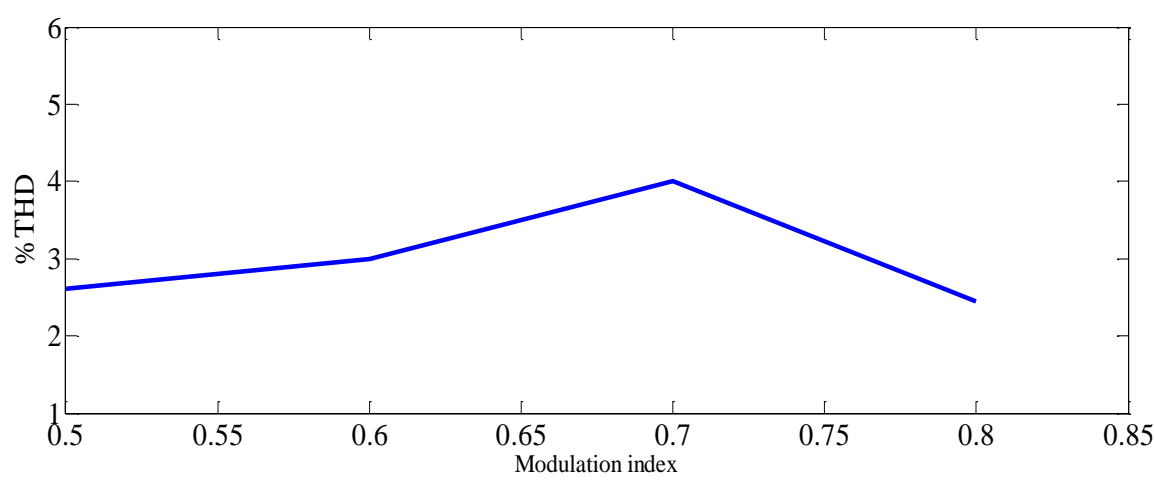

Figure 6. \% THD vs modulation index

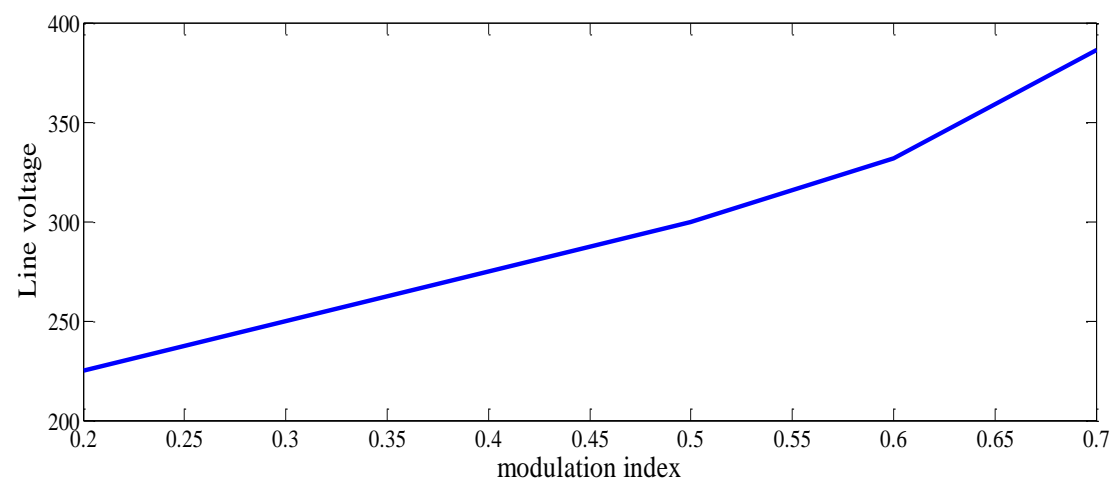

Figure 7. Fundamental component vs modulation index 


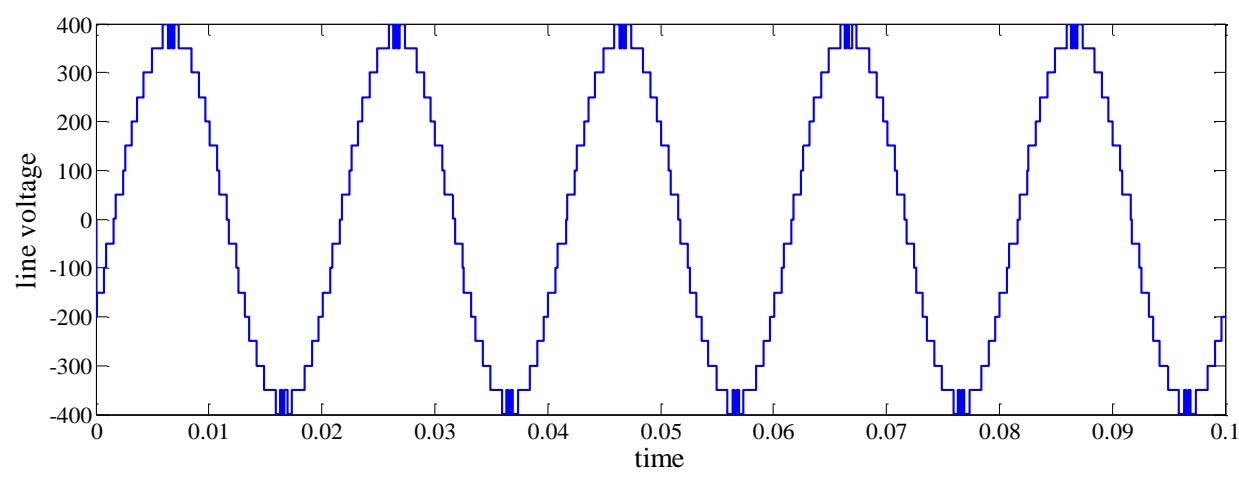

(a)

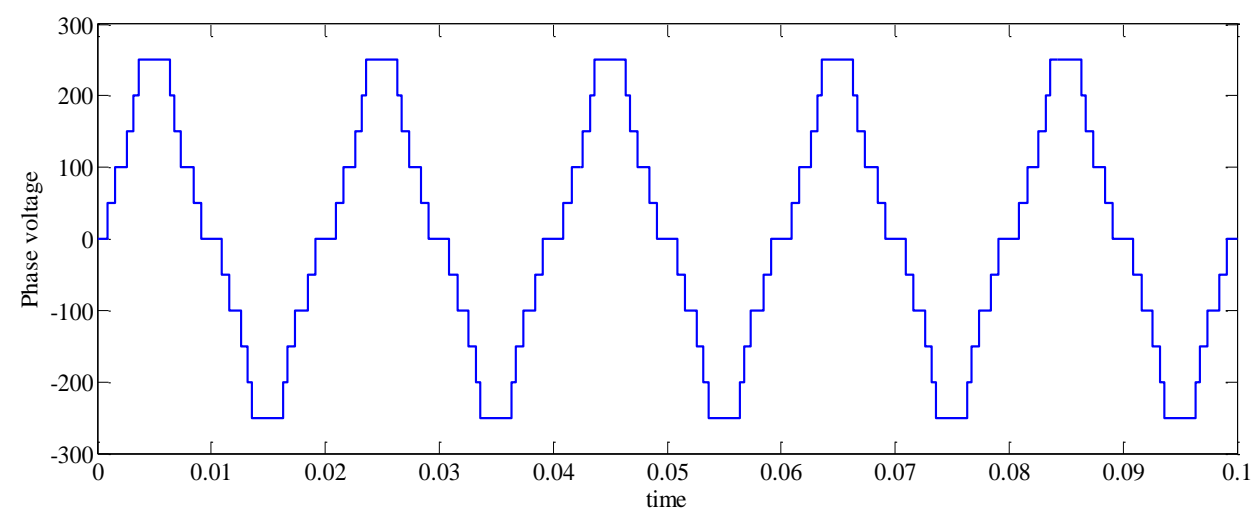

(b)

Figure 8. (a)Line voltage waveform (b)Phase Voltage Waveform

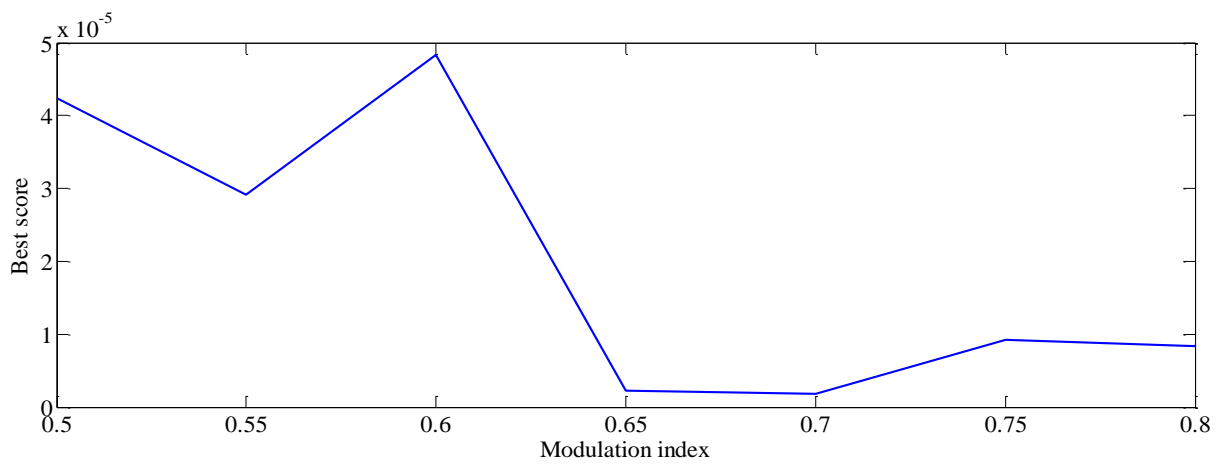

Figure 9. Best score vs modulation index

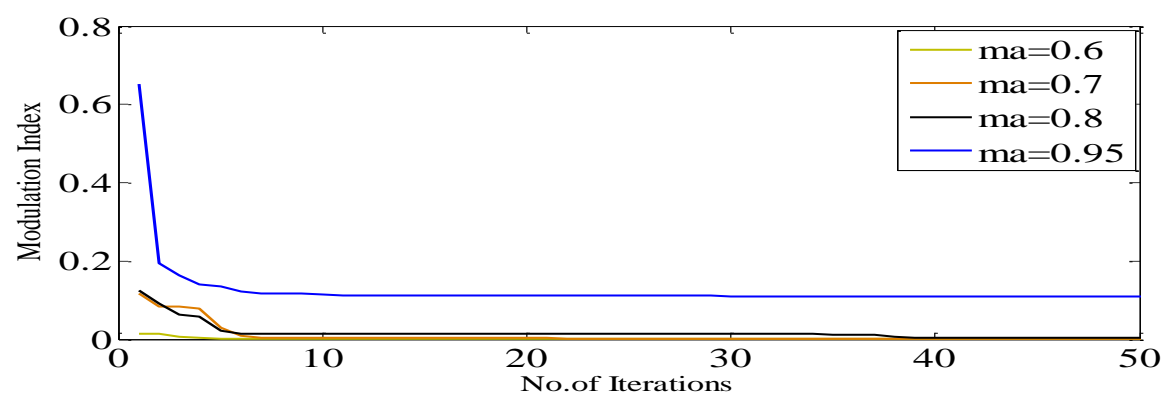

Figure 10. Convergence curve 
Table 2. Comparision of THD Using Different Algorithm

\begin{tabular}{cccccccc}
\hline Optimization & Modulation & \multicolumn{5}{c}{ Switching angles in degrees } & \multirow{2}{*}{ \% THD } \\
\cline { 4 - 7 } techniques[15][16] & index 'Ma' & $\alpha_{1}$ & $\alpha_{2}$ & $\alpha_{3}$ & $\alpha_{4}$ & $\alpha_{5}$ & \\
\hline Newton -Raphson & 0.8 & 6.56 & 18.93 & 27.17 & 45.12 & 61.87 & 5.55 \\
method & & & & & & & \\
LSHADE /Epsin & not given & 5.49 & 16.68 & 28.58 & 42.06 & 59.46 & 7.26 \\
Technique & 0.8 & 6.6 & 18.8 & 27.3 & 45.1 & 62.2 & 4.25 \\
WOA & 0.65 & 3.54 & 10.2 & 14.66 & 24.9 & 38.3 & 4.39 \\
Genetic Algorithm & 0.7 & 17.84 & 39.1 & 54.30 & 63.62 & 86.13 & 5.23 \\
Differential Evolution & Algorithm & & & & & & \\
\hline
\end{tabular}

\section{CONCLUSION}

In this paper,WOA algorithm is successfully applied to the problem of switching angle optimization in a multilevel inverter fed from equal sources.The proposed WOA algorithm scrutinizes for all probable set of results to contribute the least THD. From the results, we draw the conclusion that the suggested approach is able to reduce the lower order harmonics while retaining the fundamental output voltage. The $5^{\text {th }}, 7$ th, 11 th, 13this found out to be less than less than $1 \%$ whereas the higher order odd harmonics up to39th was found out to be $4.25 \%$. It is observed that with WOA algorithm the results are comparatively better when compared with other algorithms along with its ability to escape local minima.

\section{REFERENCES}

[1] J. Rodríguez, S. Member, J. Lai, and S. Member, "Multilevel Inverters : A Survey of Topologies , Controls , and Applications," vol. 49, no. 4, pp. 724-738, 2002.

[2] M. Malinowski et al., "A Survey on Cascaded Multilevel Inverters," vol. 57, no. 7, pp. 2197-2206, 2010.

[3] W. A. Halim, T. Noor, A. Tengku, K. Applasamy, and A. Jidin, "Selective Harmonic Elimination Based on Newton-raphson Method for Cascaded H-bridge Multilevel Inverter," vol. 8, no. 3, pp. 1193-1202, 2017.

[4] N. Prabaharan and K. Palanisamy, "A comprehensive review on reduced switch multilevel inverter topologies , modulation techniques and applications," Renew. Sustain. Energy Rev., vol. 76, no. January 2016, pp. 1248-1282, 2017.

[5] T. Porselvi, K. Deepa, and R. Muthu, "FPGA Based Selective Harmonic Elimination Technique for Multilevel Inverter," vol. 9, no. 1, pp. 166-173, 2018.

[6] D. Committee, I. Power, and E. Society, "IEEE Recommended Practice and Requirements for Harmonic Control in Electric Power Systems IEEE Power and Energy Society," vol. 2014, 2014.

[7] H. Taghizadeh and M. T. Hagh, "Harmonic Elimination of Cascade Multilevel Inverters with Nonequal DC Sources Using Particle Swarm Optimization,” vol. 57, no. 11, pp. 3678-3684, 2010.

[8] R. Taleb, M. Helaimi, D. Benyoucef, and Z. Boudjema, "Genetic Algorithm Application in Asymmetrical 9-Level Inverter," vol. 7, no. 2, 2016.

[9] R. P. Aguilera et al., "Selective Harmonic Elimination Model Predictive Control for Multilevel Power Converters," IEEE Trans. Power Electron., vol. 32, no. 3, pp. 2416-2426, 2017.

[10] S. M. Inverter, M. Ahmed, A. Sheir, M. Orabi, and S. Member, "Real-Time Solution and Implementation of Selective Harmonic Elimination of," vol. 5, no. 4, pp. 1700-1709, 2017.

[11] J. Kumar, B. Das, and P. Agarwal, "Selective harmonic elimination technique for a multilevel inverter," Fifteenth Natl. Power Syst. Conf., no. December, pp. 608-613, 2008.

[12] P. Q. Dzung, N. T. Tien, N. D. Tuyen, and H. Lee, "Selective Harmonic Elimination for Cascaded Multilevel Inverters Using Grey Wolf Optimizer Algorithm,” pp. 2776-2781, 2015.

[13] S. Mirjalili and A. Lewis, "Advances in Engineering Software The Whale Optimization Algorithm," Adv. Eng. Softw., vol. 95, pp. 51-67, 2016.

[14] I. J. Electron, C. Aeü, B. Nayak, B. Misra, and T. R. Choudhury, "Meta-heuristic optimization algorithms for design of gain constrained state variable fi lter," Int. J. Electron. Commun., vol. 93, no. February, pp. 7-18, 2018.

[15] S. Sudha, T. Thakur, and J. Kumar, "Harmonic elimination of a photo-voltaic based cascaded H-bridge multilevel inverter using PSO ( particle swarm optimization ) for induction motor drive," Energy, vol. 107, pp. 335-346, 2016.

[16] P. P. Biswas, N. H. Awad, and P. N. Suganthan, "Minimizing THD of Multilevel Inverters with Optimal Values of DC Voltages and Switching Angles using LSHADE-EpSin algorithm," no. June, 2017. 